\title{
Same day diagnosis of Down's syndrome and sex in single cells using multiplex fluorescent PCR
}

\author{
I Findlay, P Matthews, T Tóth, P Quirke, Z Papp
}

\begin{abstract}
The major reason for prenatal diagnosis lies in the detection of trisomies, particularly trisomy 21 (Down's syndrome). Current techniques require lengthy laboratory procedures and high costs. Furthermore, diagnosis is often not possible if the sample is of small size or is contaminated. An alternative method, quantitative fluorescent polymerase chain reaction (PCR) of short tandem repeats (STRs), can also be used to diagnose trisomies and it has the advantage that a result is obtained within five to eight hours. However, this method is currently limited to relatively large amounts of sample, which restricts diagnostic confidence and value. Recently, genetic diagnosis using fluorescent PCR has been applied at the single cell level but is limited to sex or single gene defect diagnosis. This study, using quantitative multiplex fluorescent PCR, provides for the first time simultaneous diagnosis and confirmation of sex and trisomy in single cells. Two markers for chromosome 21 increase diagnostic confidence, informativeness, and confirmation. This system is rapid (five hours), reliable, and accurate and we believe that it will be more cost effective than alternative methods. The technique has direct application to preimplantation genetic diagnosis, early prenatal diagnosis, and other diagnostic systems where sample size is limited.

(F Clin Pathol: Mol Pathol 1998;51:164-167)
\end{abstract}

Molecular Oncology, Algernon Firth Building, University of Leeds, Leeds LS2 9LN, UK

I Findlay

P Matthews

P Quirke

Semmelweis

University Medical

School, Department of

Obstetrics and

Gynaecology,

Molecular Genetics

Laboratory, Baross u.

27, H 1088, Budapest,

Hungary

T Tóth

Z Papp

Correspondence to:

Dr Findlay.

Accepted for publication 9 April 1998
Keywords: Down's syndrome; trisomy; prenatal diagnosis; multiplex fluorescent polymerase chain reaction; short tandem repeats

Chromosomal abnormalities are the most frequent genetic disorders seen in both liveborn babies and miscarriages. ${ }^{1}$ Trisomies, the most frequent chromosomal disorder, account for $\sim 53 \%$ of all chromosomal abnormalities in early fetal deaths. ${ }^{1}$ The most frequent trisomy is Down's syndrome (trisomy 21 ), which occurs in about one in 600 newborns, and is a major reason for prenatal diagnosis. ${ }^{1}$ Such diagnosis is usually performed by means of karyotyping and depends on analysis at 11-18 weeks of gestation. As well as high costs (approximately $£ 150$ for karyotyping), the lengthy culture procedure results in a significant delay (generally until 13-20 weeks of gestation) until the diagnosis can be made. This results in either a long delay for the mother before reassurance about a healthy pregnancy or the prospect of a late termination in the second trimester, which is both emotionally and physically traumatic. Second trimester terminations require surgery, rather than medical treatment, which exposes the patient to an increased risk of mortality.

In addition, karyotyping is not always possible, especially when the numbers of cells obtained are limited, where cell culture fails (in $1-2 \%$ of patients), ${ }^{2}$ or when the culture is contaminated. Maternal contamination rates of up to $10-14 \%$ have been reported even in the most experienced laboratories. ${ }^{34}$ In these cases, diagnosis is extremely difficult if not impossible, even with molecular genetic techniques such as the polymerase chain reaction (PCR) or fluorescent in situ hybridisation (FISH).

Therefore, an alternative method providing rapid (same day) diagnosis of small numbers of cells would be extremely valuable. One such technique, which is both rapid and inexpensive, is the quantitative fluorescent PCR (F-PCR) amplification of short tandem repeats (STRs). This method, using STRs specific for chromosome 21, has previously been used to diagnose trisomy $21 .^{5}$ The quantitative nature of this technique allows the amount of PCR product to be determined and thus the amount of each PCR product from each allele to be compared. This allows the amount of one allele in relation to the other to be calculated. ${ }^{6}$

Although this method was first described by Mansfield in 1993, there have been only a few reports applying the technique clinically to trisomy detection in prenatal diagnosis. This has been mainly the result of the relatively high numbers of cells required and the relatively low amount of information produced by such a diagnosis when using a single STR marker. Although an F-PCR system was used recently by Pertl et al on amniotic fluid, ${ }^{7}$ this method was subsequently shown to be suboptimal because of the primers used. ${ }^{8}$

An alternative multiplex F-PCR method has been used previously for genetic diagnosis of sex and single gene defects in single cells, ${ }^{9}$ and this method was adapted for trisomy detection. This system can also be used to determine the origin of the extra chromosome and, if maternally derived, whether the extra chromosome is derived from meiosis I or meiosis II. ${ }^{10}$

\section{Materials and methods}

Thirty five single dissociated cells from four known trisomy 21 fetal livers and 18 single dissociated cells from two known disomic fetal livers were analysed. 
Table 1 Primer details

\begin{tabular}{lllll}
\hline Locus & Location & Primer name & Sequence & $\begin{array}{l}\text { Fluorescent } \\
\text { label }\end{array}$ \\
\hline HUMAMGXA & Xp22.1-p22.3 & AMEL A & CCC TGG GCT CTG TAA AGA ATA GTG & FAM \\
HUMAMGY & Yp11.2 & AMEL B & ATC AGA GCT TAA ACT GGG AAG CTG & HEX \\
D21S167 & $21 \mathrm{q} 22.2$ & D21S167 1 & TGC CCT GAA GCA CAT GTG T & FAM \\
& $21 \mathrm{q} 21$ & D21S167 2 & TCC TTC CAT GTA CTC TGC A & \\
D21S11 & D21S11 1 & ATA TGT GAG TCA ATT CCC CAA G & \\
& & D21S11 & TGT ATT AGT CAA TGT TCT CCA G & \\
\hline
\end{tabular}

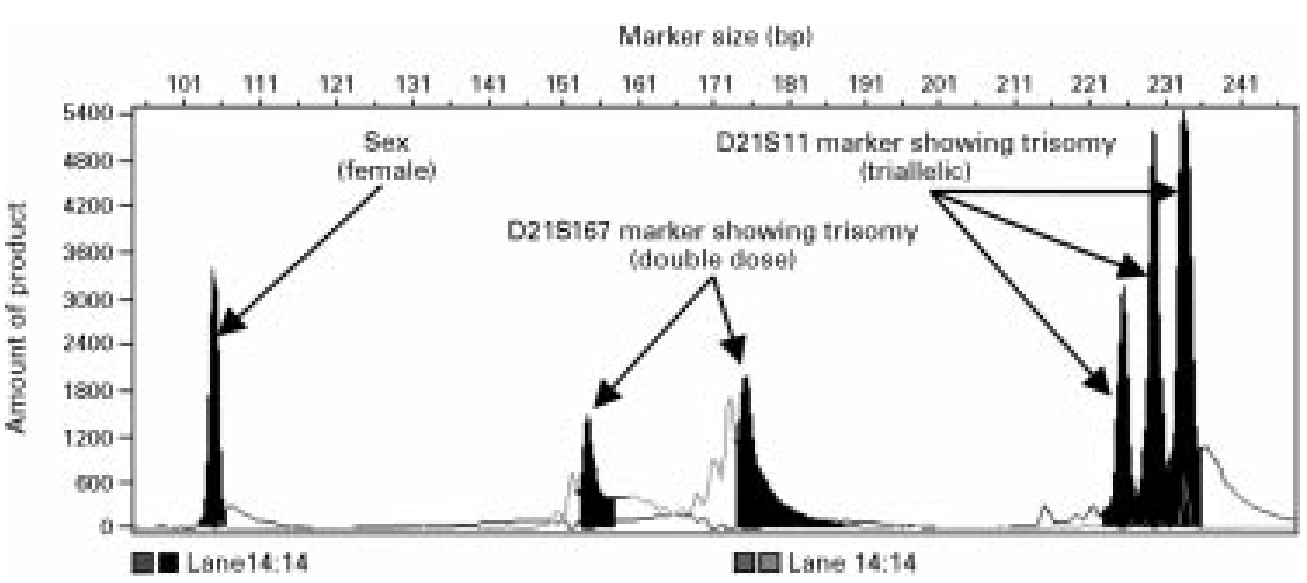

Figure 1 Double dose is determined by comparing peak areas (rather than peak size) of each allele. This figure shows trisomy diagnosis at the single cell level using multiple trisomic markers. The sex of the cell is also shown. The D21S167 marker indicates trisomy status by having double dose results (1:2 ratio). Trisomy status is confirmed by the D21S11 marker, which has a triallelic signal.

Cell lysis was not necessary for single cell samples. ${ }^{11}$ Three fluorescent PCR primers were used in each PCR, one primer for sexing and two for trisomy 21 detection. The amelogenin gene, ${ }^{12}$ used previously for single cell sexing ${ }^{913}$ and two primer sets, D21S1 $1^{14}$ and D21S167, ${ }^{15}$ were used for trisomy 21 detection. Heterozygosity rates of the D21S11 and D21S167 STRs are $89 \%$ and $82 \%$, respectively. Details of the primers are given in table 1.

The PCRs were performed in $25 \mu 1$ reaction volumes using $1 \times$ PCR buffer (reaction buffer IV; Advanced Biotechnologies Ltd, Leatherhead, Surrey, UK), $200 \mu \mathrm{M}$ of each dNTP (MBI, Lithuania), $1.5 \mathrm{mM}$ of $\mathrm{MgCl}_{2}, 0.6 \mathrm{U}$ of Taq polymerase (Thermoprime Plus; Advanced Biotechnologies Ltd). For the D21 multiplex, primers were added such that the final amount of each primer in each PCR tube was 3 pmoles amelogenin, 15 pmoles of D21S11, and 3 pmoles of D21S167. A $25 \mu \mathrm{l}$ aliquot was added to each sample undergoing the PCR and mixed well. The PCR comprised

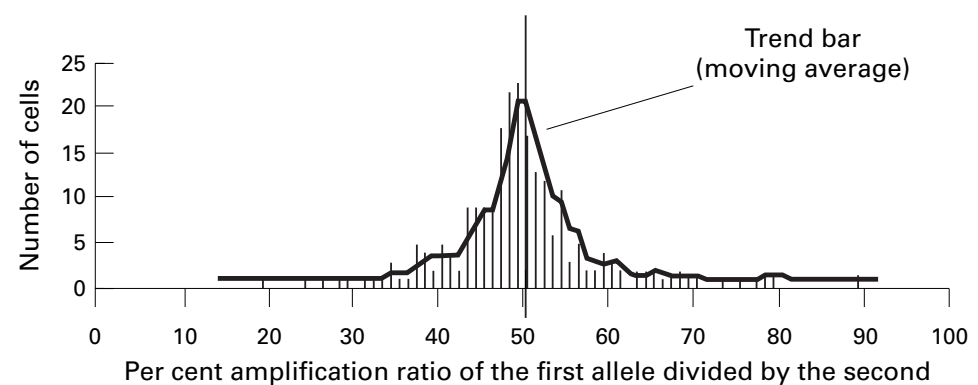

Figure 2 All calculations were based on peak areas, which were estimated automatically as a measure of product yield by the Genescan software. This figure shows that a range of efficiency is seen for each allele. The trend bar indicates that the graph is similar to a normal distribution curve and that most of the ratios are between $40 \%$ and $60 \%$. an initial denaturation step of $95^{\circ} \mathrm{C}$ for five minutes, followed by 41 cycles of $95^{\circ} \mathrm{C}$ for 45 seconds, $60^{\circ} \mathrm{C}$ for 45 seconds, and $72^{\circ} \mathrm{C}$ for 45 seconds, then a final extension step of $72^{\circ} \mathrm{C}$ for 10 minutes. The PCR products were stored at $4^{\circ} \mathrm{C}$ until analysis.

DNA was analysed by the method reported by Findlay and Quirke, ${ }^{16}{ }^{17}$ except that samples were not co-loaded and only ROX 350 was used as the internal standard. Samples that gave an overamplified response were run again at a $10 \%$ dilution.

Trisomy was defined as either a triallelic signal or cell ratio (amount of PCR product from the first allele divided by the product from the second allele, where ratios $>4$ or $<0.25$ in three cases were disregarded as a result of extreme preferential amplification) of $<0.7$ or $>1.3$. Disomy was defined as a ratio between 0.7-1.3. Where triallelic signals were not seen, the aggregated ratios for three or more cells were used. Preferential amplification is an important consideration in trisomy diagnosis using double dose responses because overamplification of one allele might result in misdiagnosis, either because of enhanced amplification of a smaller allele falsely indicating disomy status or decreased amplification in a disomic allele falsely indicating trisomy status.

All cells were run "blind"- the operator did not know the trisomy status until all results were completed and tabulated. Trisomy and sex results were then obtained from karyotype data.

\section{Results}

One or more D21 markers were seen in all of the trisomic and disomic cells (35 of 35 and 19 of 19, respectively). Both D21 markers were 
Table 2 D21S167 and D21S11 short tandem repeat amplification ratios in single cells

\begin{tabular}{|c|c|c|c|c|c|c|c|c|}
\hline $\begin{array}{l}\text { Sample number } \\
\text { (number of cells) }\end{array}$ & $\begin{array}{l}\text { D21S167 } \\
\text { median }\end{array}$ & $\begin{array}{l}\text { D21S167 } \\
\text { ratio range }\end{array}$ & $\begin{array}{l}\text { D21S11 } \\
\text { median }\end{array}$ & $\begin{array}{l}\text { D21S11 ratio } \\
\text { range }\end{array}$ & $\begin{array}{l}\text { Trisomy } \\
\text { status by } \\
\text { PCR }\end{array}$ & $\begin{array}{l}\text { Sex by } \\
\text { PCR }\end{array}$ & $\begin{array}{l}\text { Trisomy status } \\
\text { by karyotyping }\end{array}$ & $\begin{array}{l}\text { Sex by } \\
\text { karyotyping }\end{array}$ \\
\hline $203(8)$ & 1.06 & $0.68-1.22$ & 1.02 & $0.52-2.43$ & Disomic & Female & Disomic & Female \\
\hline $211(10)$ & 1.22 & $1.11-1.42$ & 0.95 & $0.65-1.06$ & Disomic & Male & Disomic & Male \\
\hline $204(7)$ & 2.42 & $1.21-3.14$ & 1.61 & $1.05-2.43$ & Trisomic & Female & Trisomic & Female \\
\hline $133(10)$ & 0.64 & $0.28-0.98$ & Triallelic & NA & Trisomic & Male & Trisomic & Male \\
\hline $201(9)$ & 1.55 & $0.86-3.5$ & 1.40 & $0.89-1.75$ & Trisomic & Male & Trisomic & Male \\
\hline $124(9)$ & 2.54 & $1.34-3.78$ & 1.82 & $0.84-2.71$ & Trisomic & Female & Trisomic & Female \\
\hline
\end{tabular}

Trisomy 21 status of single cells, where disomy is defined as an amplification ratio between 0.7 and 1.3 and trisomy is defined either as a triallelic signal or as an amplification ratio $<0.7$ or $>1.3$. Although there is some variability in the range for each sample, the correct trisomy status diagnosis was made in each case. Therefore, the assessment of trisomy by PCR agrees with the results obtained with karyotyping. In addition, sexing results agreed with those obtained by karyotyping. Although sample 133 was diagnosed as trisomy because of its triallelic pattern, ratios are included for completeness. NA, not available.

seen in 26 of 35 of the trisomic samples and 15 of 19 of the disomic samples. In all cases, the STR results confirmed the known karyotype and there were no cases where one STR indicated trisomy and the other disomy. Figure 1 shows trisomy diagnosis at the single cell level using two trisomic markers. The need for two or more chromosome 21 markers was demonstrated because preferential amplification was seen in both STRs (fig 2).

A range of preferential amplification for each D21 marker was seen in both trisomic and disomic samples. Table 2 shows the aggregated ratios of three or more cells and the disomic range seen for D21S11 and D21S167.

Sex diagnosis was obtained simultaneously in 22 of 35 single trisomic cells and 12 of 19 single disomic cells.

\section{Discussion}

This technique is rapid and has high reliability, accuracy, and increased confidence for single cell trisomy 21 detection because it can provide simultaneous confirmation. This system has several significant advantages over conventional karyotyping for trisomies:

- Time taken for diagnosis. Diagnosis can be obtained within five to six hours rather than two weeks. This same day diagnosis would allow rapid patient reassurance or pregnancy termination if required.

- Reduced costs. The costs of karyotyping (£150-200/sample) are significantly higher than for multiplex fluorescent PCR (approximately $£ 30$ /sample). Although fluorescent PCR does require an intial outlay of approximately $£ 50000$ to purchase the DNA sequencer, it allows a wide range of diagnoses to be undertaken.

- Number of cells required. Karyotyping needs very high numbers of cells (thousands) for reliable results, whereas fluorescent PCR requires as few as three cells (or even single cells). Results can be obtained even when conventional methods have failed.

- The effects of contamination are reduced. Because these analyses are performed on single cells, results can be obtained even if the sample is heavily contaminated with maternal or other cells.

The possibility of multiplexing several STRs on chromosome 21 in the same PCR provides:

- Increased information. If one STR fails to amplify, a diagnosis can be obtained from the other STR.
- Increased accuracy. If allelic dropout occurs in one STR, then the other STR should provide a result. Allelic dropout, where one allele fails to amplify, is an important problem in single cell analysis ${ }^{18}$ and can result in misdiagnosis. Allelic dropout occurs at a rate of $5-10 \%$, depending on the primer used. ${ }^{16}{ }^{18}$ However, when using two STRs, the possibility of allelic dropout should be reduced from $10 \%$ to $1 \%$ (10\% of $10 \%$ ) for both STRs.

- Confirming the diagnosis. If both STRs give concordant results, the confidence that the result is correct will be increased.

However, for multiplexing to succeed multiple cells from the same sample must be used when triallelic results are not obtained. This increases time and cost and reduces the number of individual tests possible from one sample. However, these negative aspects are compensated for by the fact that concordant results confirm the diagnosis.

If the cell is known to be heterozygous, perhaps by previous testing of the parents in preimplantation genetic diagnosis or prenatal diagnosis, then the usefulness of trisomy diagnosis will increase. For example, if the mother is known to be heterozygous for both D21S11 and D21S167, the trisomy detection rates for triallelic results will increase from $68 \%$ to $75 \%$, and by double dose from $23 \%$ to $25 \%$. Uninformative results will decrease from $10 \%$ to $0 \%$. This demonstrates the importance of selecting STRs with as high a heterozygosity rate as possible and the need for multiple markers.

This technique has important applications in conventional prenatal diagnosis and preimplantation diagnosis of genetic disease. In addition, it has potential for use in the diagnosis of trisomies from fetal cells in the maternal circulation.

1 Hook EB. Chromosome abnormalities. In: Brock DJH, Rodek $\mathrm{CH}$, Ferguson-Smith MA, eds. Prenatal diagnosis and screening. Edinburgh: Churchill Livingstone, 1992:351-93

2 Reid R, Sepulveda W, Kyle PN, et al. Amniotic-fluid culture failure-clinical-significance and association with aneuploidy. Obstet Gynecol 1996;87:588-92.

3 Roberts E, Duckett DP, Lang GD. Maternal cell contamination in chorionic villus samples assessed by direct preparation and three different culture methods. Prenat Diagn 1988;8:635-40.

4 Deandreis C, Simoni G, Rossella F, et al. HIV-1 proviral DNA-polymerase chain-reaction detection in chorionic villi after exclusion of maternal contamination by variable number of tandem repeats analysis. AIDS 1996;10:711-15.

5 Adinolfi M, Sherlock J, Tutschek B, et al. Detection of fetal cells in transcervical samples and prenatal diagnosis of
chromosomal abnormalities. Prenat Diagn 1995;15:943-9. 
6 Mansfield ES. Diagnosis of Down syndrome and other aneuploidies using quantitative polymerase chain reaction and small tandem repeat polymorphisms. Hum Mol Gene 1993;2:43-50.

7 Pertl B, Weitgasser U, Kopp S, et al. Rapid detection of trisomies 21 and 18 and sexing by quantitative fluorescent multiplex PCR. Hum Genet 1996;98:55-9.

8 Tóth T, Findlay I, Papp C, et al. Prenatal detection of trisomy 21 by fluorescent polymerase chain reaction: importance of primer selection and criticism of an earlier report. Hum Genet 1997;101:383.

9 Findlay I, Urquhart A, Quirke P, et al. Simultaneous DNA status from a single cell. Hum Reprod 1995;10:1005-13.

10 Kotzot D, Bundscherer G, Bernasconi F, et al. Isochromosome $18 \mathrm{p}$ results from maternal meiosis-II nondisjunction. Eur F Hum Genet 1996;4:168-74.

11 Findlay I, Lilford R. Sources and detection of contamination in preimplantation diagnosis [abstract 101]. Proceedtion in preimplantation diagnosis [abstract 101]. Proceed-
ings of XIII annual scientific meeting of Fertility Society of Ausings of XIII ann
tralia. 1994.

12 Levinson G, Fields RA, Harton GL, et al. Reliable gender screening for human pre-implantation embryos, using multiple DNA target-sequences. Hum Reprod 1992;7 1304-14.
13 Findlay I, Urquhart A, Quirke P, et al. Genetic diagnosis of a single cell: a multiplex fluorescent PCR using seven primers to diagnose sex and DNA fingerprint. Miami Biol Technology short reports proceedings of the 1994 Miami Bio/Technology European symposium, advances in gene technology: molecular biology and human genetic disease, Vol 5. Oxford: IRL at Oxford University Press, 1994:62.

14 Sharma V, Litt $M$. Tetranucleotide repeat polymorphism at the D21S11 locus. Hum Mol Genet 1992;1:67.

15 Guo Z, Sharma V, Patterson D, et al. TG repeat polymorphism at the D21S167 locus. Nucleic Acids Res 1990;18:4967.

16 Findlay I, Quirke P. Part I. Fluorescent polymerase chain reaction: a new method allowing genetic diagnosis and DNA fingerprinting of single cells. Human Reproduction Update 1996;2:137-52.

17 Findlay I, Quirke P. Part II. Detailed technique of fluorescent polymerase chain reaction. Human Reproduction Update 1996;2:CD-ROM ed.

18 Findlay I, Ray P, Quirke P, et al. Allelic dropout and preferential amplification in single cells and human blastomeres: implications for preimplantation diagnosis of sex and cystic fibrosis. Hum Reprod 1995;10:1609-18. 